\title{
Budget squeeze: Cutting clinicians hurts patients
}

The ranks of senior public healthcare administrators swelled by $12 \%$ over the past 3 years v. a $3.5 \%$ growth among all physicians, pharmacists and pathologists over the same period. This previously unpublicised skewed progression has further bolstered appeals by healthcare professional groups to stop the wide-scale, debilitating freezing of clinical posts.

Izindaba's extraction and review of national public healthcare staff data brings some factual context to ongoing political rhetoric over whether or not clinical posts are being frozen in the current severely constrained economic climate. The South African Medical Association (SAMA) and the Rural Health Advocacy Project (RHAP) claim that health minister Dr Aaron Motsoaledi is playing political semantics by denying that his provincial healthcare counterparts are 'freezing' posts, asking him and finance minister Pravin Gordhan to address the 'real issue' of funding and protecting critical healthcare posts. The Izindaba review lends credence to longstanding speculation that hard-pressed provincial chief financial managers are panicking at their shrinking budgets, particularly after unions (mainly the National Education and Health Workers' Union, NEHAWU) won a $10 \%$ wage increase totalling ZAR69 billion over the 2015/16 financial year (part of a 3-year settlement). The implications for healthcare delivery - without alternative extra sources of revenue and with the pending expensive implementation of actual National Health Insurance funding are dire. The widespread blocking or closing down of critical clinical service delivery posts from December last year through January (when most doctors and nurses were seeking them) is, according to SAMA, 'dangerously short-sighted'. SAMA Chairperson Dr Mzukisi Grootboom says that not only will it hurt the most vulnerable patient populations and increase existing billion-rand litigation claims, but it will aggravate work pressures as clinical staff are stretched to breaking point after colleagues leave, creating a 'domino effect' and leading to the potential collapse of untenably staffed district hospitals and community health centres. In spite of the overall national increase from 18701 clinical staff in September 2012 to 19352 (35\%) by
September 2015, this clinical staff component suddenly plummeted by 327 members $(-1.7 \%)$ from March to September last year - exactly when financial austerity measures were introduced. Nursing numbers virtually flatlined from 134153 in September 2012 to 134453 in September 2013 and 134811 in September 2014 before suddenly increasing by $1.2 \%$ to 136439 in September last year.

With an estimated 3\% staff turnover, the state should be able to replace 9000 posts without increasing expenditure. Significant savings could be achieved by only filling say 7000 posts, yet unless a pragmatic process for quickly refilling critical posts is in place, the net result could be near-chaos, given the 400000 annual increase in AIDS patients alone.

\section{Budget-breakers remain stubbornly in place}

Says Daygan Eagar, programme manager for the RHAP and veteran provincial healthcare financial watchdog: 'While bringing in community service doctors made a huge difference to delivery, and although it increased costs, the glaring primary cost factors have always been higher-than-inflation salary increases and a rapidly growing administrative cadre.' This happened regardless of how the economy was performing, with the current strain on the national fiscus hugely constricting current provincial budget allocations.

Both Eagar and Izindaba Treasury sources agreed that government negotiators 'tend to give in' at wage negotiations with the powerful NEHAWU. Grootboom said that although mention was made of a process whereby critical posts could be unfrozen and advertised, the reality was that this was a long bureaucratic procedure that sometimes required approval from the premier's office. Izindaba's $11 \%$ administrative expansion figure depicts health directors level up to directors-general. Provinces that have frozen clinical healthcare staff posts are North West, the Eastern Cape, KwaZuluNatal, Mpumalanga and the Free State. Eagar said that in his experience, even when 'exceptional circumstances' were proven and budgets could be freed up, it took between 6 months and a year to fill an unfrozen post.

Over the past 3 years the total public sector healthcare staff complement (clinical and nonclinical) has dropped from 314859 people to $309367(-1.8 \%)$ - this after continual growth up to 2012, although Izindaba sources stressed that this figure, while illustrating a marked trend, might not be entirely accurate owing to 'data collection issues'.

\section{Who will care for the growing AIDS population?}

With an estimated 3\% staff turnover, the state should be able to replace 9000 posts without increasing expenditure. Significant savings could be achieved by only filling say 7000 posts, yet unless a pragmatic process for quickly refilling critical posts is in place, the net result could be near-chaos, given the 400000 annual increase in AIDS patients alone.

National health department staff figures show that as of September last year there were 511 senior managers (directors up to directorsgeneral) - up from 457 in September 2012 (a $12 \%$ increase), with a gradual upward creep every year in between. In the category of 'core administration' (low-level admin posts such as financial clerks, credit controllers, materialrecording and transport clerks, human resource clerks, managers and cashiers), numbers increased by 4005 between 2013 and 2015 (also up 12\%). In September 2012 there were 34284 core admin staff, dropping slightly to 33331 in September 2013 and then inexorably increasing to 36136 in September 2014 and up again to 37336 in September last year.

Izindaba sources said that some 'shrewd innovative thinking' would be necessary to correct the current skewed human resource healthcare delivery model.

\section{Chris Bateman}

chrisb@hmpg.co.za

$S$ Afr Med J 2016;106(4):321

DOI:10.7196/SAMJ.2016.v106i4.10762 